\title{
Energy Drinks and Atrial Fibrillation: An Unusual Case of Caution
}

\author{
Muhammad Hanif $^{1}$, Sana Saleem ${ }^{2}$, Sidra Naz $^{3}$, FNU Sundas ${ }^{1}$ \\ 1. Internal Medicine, Khyber Medical College, Peshawar, PAK 2. Cardiology, District Headquarters Teaching Hospital, \\ Sargodha, PAK 3. Internal Medicine, University of Health Sciences, Lahore, PAK
}

Corresponding author: Sana Saleem, sanasaleem197@gmail.com

\begin{abstract}
The most well-known type of cardiovascular arrhythmia in the United States and worldwide is atrial fibrillation (AF). Generally, 2.3 million individuals are determined to have AF in the United States. Energy drinks contain caffeine, taurine, theophylline, and sugars that enhance alertness. Consumption of energy drinks is mounting in the young population and has been associated with AF, regardless of the lack of conclusive evidence in the literature. This is a case report of a 22 -year-old male without any significant cardiac history who was diagnosed with AF following intake of energy drinks.
\end{abstract}

Categories: Cardiology, Emergency Medicine, Internal Medicine

Keywords: cardiac arrhythmia, atrial fibrillation, energy drink

\section{Introduction}

The prevalence of atrial fibrillation (AF) increases with age, and young adults are at low risk (less than $1 \%$ of patients with $\mathrm{AF}$ are $<60$ years of age) [1]. Consumption of stimulants such as caffeine in young adults has been soaring and is a conceivable trigger of AF, as it increases the heart rate. Di Rocco et al. reported AF in two Caucasian adolescent males after excessive caffeine ingestion [2]. Similarly, three cases of AF with fast ventricular response after consuming energy drink were reported by Mattioli et al. All the patients were successfully cardioverted spontaneously and after pharmacological treatment [3]. Here, we present a case of 22-year-old male with no previous comorbidities who was diagnosed with AF after consuming energy drinks.

Review began 09/24/2020 Review ended 10/03/2020 Published 10/05/2020

\section{(c) Copyright 2020}

Hanif et al. This is an open access article distributed under the terms of the Creative Commons Attribution License CC-BY 4.0., which permits unrestricted use, distribution, and reproduction in any medium, provided the original author and source are credited.

\section{Case Presentation}

A 22-year-old male student with no significant past medical or family history presented to the emergency department (ED) early in the morning with complaints of shortness of breath. He had consumed two energy drinks prior to his semester examination that day. Initially, on consuming the drink, the patient felt energetic and alert. However, after an hour, he started feeling short of breath and restless and vomited. The caffeine and taurine content of the drink was $111 \mathrm{mg}$. On examination, the patient appeared restless, with a heart rate in the $150 \mathrm{~s}$, a heartbeat that was irregular without murmurs, rubs, or gallops, and a blood pressure of 115/80 mmHg. An electrocardiogram (EKG) was obtained that showed AF with rapid ventricular response (Figure 1). Work-ups for thyroid functions and serum electrolytes (potassium, sodium, calcium, phosphate, and magnesium) were performed, the results of which were normal. Echocardiogram showed a structurally normal heart with an ejection fraction of 55\%. Urine toxicology was sent, which revealed no toxic substance. The patient was admitted for further evaluation of his AF. Spontaneous resolution of the AF occurred during the observation. The patient was advised follow up after one month. An EKG and echocardiogram were repeated on the follow-up, which were normal. 


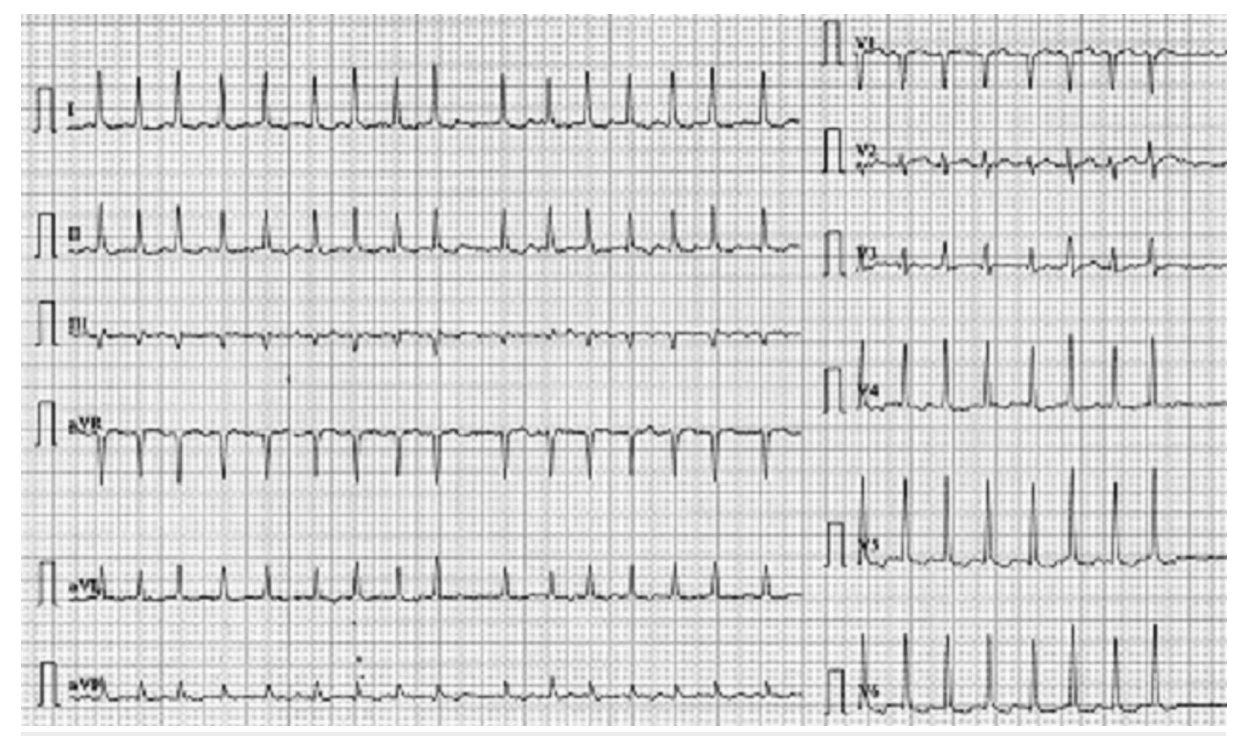

FIGURE 1: EKG showing atrial fibrillation with rapid ventricular response (ventricular rate: 150 beats per minute).

EKG, electrocardiogram

\section{Discussion}

Energy drinks are advertised across the world and are popular among young adults. According to self-repot surveys conducted by Seifert et al. [4], 30\%-50\% of adolescents and young adults consume energy drinks. The caffeine content varies from $50 \mathrm{mg}$ to $500 \mathrm{mg}$ per bottle [5]. Herbs, ginseng, and riboflavin are found in energy drinks such as Red Bull and Monster [6]. However, complications including insomnia, jitters, nervousness, high blood pressure, elevated heart rate, coronary artery spasm, coronary artery dissection, prolonged QT interval, and supraventricular arrhythmia can occur [7]. Few case reports provide evidence of $\mathrm{AF}$, though a case of supraventricular tachycardia was reported in a 23-year-old woman without any cardiac medical history; the mechanism of this phenomenon is yet to be understood [8]. Caffeine is thought to play a role in neurohormonal stimulation and activation of the sympathetic autonomic nervous

system [9]. Several recent studies have investigated the correlation between chronic caffeine consumption and AF; however, no significant increase in risk was established [10]. The amounts of caffeine, sugar, and sodium in energy drinks are much higher than those in sodas and other carbonated drinks [11]. Another possibility could be that the herbs in energy drinks are triggering arrhythmia. Further studies are required to determine any risk of energy drink consumption in prompting AF.

In this case report, this young adult consumed two bottles of energy drink and subsequently developed AF that spontaneously resolved to normal sinus rhythm, as seen on the EKG.

\section{Conclusions}

Few cases of AF triggered by energy drink consumption have been reported, and the mechanism linking energy drink consumption and AF has yet to be determined. With the growing consumption of energy drinks, more clinical data are required. Physicians should be aware of the possible complications of cardiac arrhythmia associated with energy drink consumption, and people should be educated about such complications in the future.

\section{Additional Information}

\section{Disclosures}

Human subjects: Consent was obtained by all participants in this study. Conflicts of interest: In compliance with the ICMJE uniform disclosure form, all authors declare the following: Payment/services info: All authors have declared that no financial support was received from any organization for the submitted work. Financial relationships: All authors have declared that they have no financial relationships at present or within the previous three years with any organizations that might have an interest in the submitted work. Other relationships: All authors have declared that there are no other relationships or activities that could appear to have influenced the submitted work.

\section{References}


1. January CT, Wann LS, Calkins H, et al.: 2019 AHA/ACC/HRS Focused Update of the 2014 AHA/ACC/HRS Guideline for the Management of Patients With Atrial Fibrillation: A Report of the American College of Cardiology/American Heart Association Task Force on Clinical Practice Guidelines and the Heart Rhythm Society [published correction appears in. J Am Coll Cardiol. 2019, 599:104-132. 10.1016/j.jacc.2019.01.011

2. Di Rocco JR, During A, Morelli PJ, Heyden M, Biancaniello TA: Atrial fibrillation in healthy adolescents after highly caffeinated beverage consumption: two case reports. J Med Case Rep. 2011, 5:18. 10.1186/1752-1947$5-18$

3. Mattioli AV, Pennella S, Farinetti A, Manenti A: Energy drinks and atrial fibrillation in young adults . Clin Nutr. 2018, 37:1073-1074. 10.1016/j.clnu.2017.05.002

4. Seifert SM, Schaechter JL, Hershorin ER, Lipshultz SE: Health effects of energy drinks on children, adolescents, and young adults. Pediatrics. 2016, 5:511-528. 10.1542/peds.2009-3592

5. Reissig CJ, Strain EC, Griffiths RR: Caffeinated energy drinks--a growing problem . Drug Alcohol Depend. 2009, 99:1-10. 10.1016/j.drugalcdep.2008.08.001

6. McCusker RR, Goldberger BA, Cone EJ: Caffeine content of energy drinks, carbonated sodas, and other beverages. J Anal Toxicol. 2006, 30:112-114. 10.1093/jat/30.2.112

7. Hussain A, Jiji AK, Barke P, Biswas S, Tabrez SSM: Cardiovascular pathologies associated with excessive energy drink consumption: a review. Crit Rev Eukaryot Gene Expr. 2018, 28:107-113. 10.1615/CritRevEukaryotGeneExpr.2018021703

8. Nagajothi N, Khraisat A, Velazquez-Cecena JL, et al.: Energy drink-related supraventricular tachycardia. Am J Med. 2008, 121:3-4. 10.1016/j.amjmed.2007.12.003

9. Myers MG: Caffeine and cardiac arrhythmias. Ann Intern Med. 1991, 114:147-150. 10.7326/0003-4819-1142-147

10. Turagam MK, Velagapudi P, Kocheril AG, Alpert MA: Commonly consumed beverages in daily life: do they cause atrial fibrillation?. Clin Cardiol. 2015, 38:317-322. 10.1002/clc.22385

11. O'Dea JA: Consumption of nutritional supplements among adolescents: usage and perceived benefits . Health Educ Res. 2003, 18:98-107. 10.1093/her/18.1.98 